\title{
OS DESAFIOS NA RELAÇÃo PROFEsSOR-ALUNO NAS AULAS DE MATEMÁTICA NO PERÍODO PANDÊMICO DA COVID-19
}

\author{
CHALLENGES IN THE TEACHER-STUDENT RELATIONSHIP IN MATHEMATICS CLASSES \\ DURING THE COVID-19 PANDEMIC PERIOD
}

DESAFÍOS EN LA RELACIÓN PROFESOR-ALUMNO EN LAS CLASES DE MATEMÁTICAS DURANTE EL PERÍODO PANDÉMICO DEL COVID-19

\section{Diego Rodrigo Habr de \\ Lima \\ iD 9}

Mestre em Matemática (UFPA)

Professor de Matemática da rede privada em Belém-PA

diegolima_10@yahoo.com.br

\section{Paulo Vilhena da Silva (iD) 9}

Doutor em Educação Matemática (UFPA)

Professor do magistério superior na UFPA

Docente do Mestrado Nacional em Matemática em Rede

(PROFMAT/UFPA)

pvilhena@ufpa.br

\section{Cristiane Ruiz Gomes (iD) 9}

Doutorado em Engenharia Elétrica (UFPA)

Professora do magistério superior na UFPA

crisruiz@ufpa.br

\section{Cristina Lúcia Dias Vaz (iD) 9}

Doutorado em Matemática

Aplicada (UNICAMP)

Professora do magistério superior na UFPA

Docente do Programa de Pós-

Graduação Criatividade e Inovação

em Metodologias de Ensino

Superior (PPGCIMES/UFPA)

cvaz@ufpa.br

\begin{abstract}
Resumo
Este trabalho visa mostrar a importância da relação professoraluno no processo de ensino aprendizagem da Matemática, por meio da análise das respostas a um questionário aplicado a alunos do $9^{\circ}$ ano do ensino fundamental de uma escola da cidade de Belém-PA. Buscamos entender quais as principais dificuldades enfrentadas por estes estudantes em aulas virtuais no período da pandemia da COVID-19 e como foi para eles a falta de interação presencial com os professores durante essas aulas. Para tanto, inicialmente realizamos uma pesquisa bibliográfica a respeito das aulas virtuais, compreendendo seus benefícios e seus desafios e encontramos, também, nos textos do psicólogo Henri Wallon, um referencial teórico para justificar como a afetividade é importante no processo de ensino-aprendizagem. Uma abordagem quali-quantitativa foi utilizada nas análises e os resultados mostram que a ruptura na relação presencial entre docente e discentes foi uma dificuldade a ser superada por todos. Palavras-chave: Afetividade. Henri Wallon. Relação professoraluno. Ensino Remoto.
\end{abstract}

Recebido em: 6 de setembro de 2021 .

Aprovado em: 12 de outubro de 2021.

Como citar esse artigo (ABNT):

LIMA, Diego Rodrigo Habr de et al. Os desafios na relação professor-aluno nas aulas de Matemática no período pandêmico da COVID-19. Revista Prática Docente, v. 6, n. 3, e087, 2021. http://doi.org/10.23926/RPD.2021.v6.n3.e087.id1321 


\section{Abstract}

This work aims to show the importance of the teacher-student relationship in the teaching-learning process of Mathematics, through the analysis of the answers to a questionnaire applied to students in the 9th grade of elementary school in a school in the city of Belém-PA. We seek to understand the main difficulties faced by these students in virtual classes during the COVID-19 pandemic period and how the lack of face-to-face interaction with teachers during these classes was for them. Therefore, we initially carried out a bibliographical research on virtual classes, understanding their benefits and challenges, and we also found, in the texts of psychologist Henri Wallon, a theoretical framework to justify how affectivity is important in the teachinglearning process. A quali-quantitative approach was used in the analysis and the results show that the rupture in the face-to-face relationship between professor and students was a difficulty to be overcome by everyone.

Keywords: Affectivity. Henri Wallon. Teacher-student relationship. Remote teaching.

\section{Resumen}

Este trabajo tiene como objetivo mostrar la importancia de la relación profesor-alumno en el proceso de enseñanzaaprendizaje de las Matemáticas, a través del análisis de las respuestas a un cuestionario aplicado a estudiantes de $9^{\circ}$ grado de primaria de un colegio de la ciudad de Belém-PA. Buscamos comprender las principales dificultades que enfrentaron estos estudiantes en las clases virtuales durante el período pandémico del COVID-19 y cómo fue para ellos la falta de interacción presencial con los docentes durante estas clases. Por ello, inicialmente realizamos una investigación bibliográfica sobre las clases virtuales, entendiendo sus beneficios y desafíos, y también encontramos, en los textos del psicólogo Henri Wallon, un marco teórico para justificar la importancia de la afectividad en el proceso de enseñanza-aprendizaje. En los análisis se utilizó un enfoque cuali-cuantitativo y los resultados muestran que la ruptura en la relación presencial entre profesores y estudiantes fue una dificultad a superar por todos.

Palabras clave: Afecto. Henri Wallon. Relación profesoralumno. Enseñanza remota. 


\section{do: $10.23926 /$ RPD.2021.v6.n3.e087.id1321}

O indivíduo é social não como resultado de circunstâncias externas, mas em virtude de uma necessidade interna.

Henri Wallon (1879 - 1962)

\section{INTRODUÇÃO}

No final de 2019 o mundo foi surpreendido pelo surgimento da COVID-19, causada pelo novo coronavírus (Sars-Cov-2), levando a Organização Mundial da Saúde (OMS) a decretar a pandemia pela doença citada em onze de março de 2020. O vírus se mostrou tão agressivo que obrigou diversos estabelecimentos, inclusive as escolas, a fecharem suas portas. A partir desta realidade, muitas instituições de ensino tiveram que pensar em alternativas para levar o ensino até seu público, sem a possibilidade, pelo menos no início, de atividades presenciais.

O ensino remoto, modalidade emergencial realizada por meio do envio de apostilas e outros materiais, vídeos gravados pelos docentes, atendimentos por meio de plataformas digitais, uso de celulares entre outras alternativas (BASSO; FIORATTI; COSTA, 2020) foi, de modo geral, a medida adotada pelas instituições escolares. Neste sentido, com as novas propostas de ensino que surgiram, muitas dúvidas também raiaram: os docentes estariam preparados para o ensino remoto? Os discentes teriam condições materiais de acompanhar as aulas? A ausência de encontros presenciais prejudicaria o desenvolvimento das aulas? As questões psicológicas surgidas nesse período atrapalhariam o desenvolvimento das atividades de professores e alunos? O aproveitamento dos discentes com relação ao aprendizado seria prejudicado?

O foco deste trabalho é analisar a relação professor-aluno e suas influências no processo de ensino aprendizagem nas aulas remotas de Matemática em uma escola da cidade de BelémPA. Para fundamentação teórica, encontramos nos textos do francês Henri Wallon (1879 1962) e seus comentadores, teorias que destacavam o desenvolvimento do indivíduo e o papel das relações sociais, que contribuíram significativamente para a compreensão da afetividade com o entendimento reflexivo sobre o desenvolvimento humano, especialmente no que concerne ao educando na escola e fora dela, como pessoa integral, completa.

Segundo Kirouac (1994), por muito tempo os estudos sobre as emoções e a afetividade eram considerados supérfluos e não científicos, ganhando destaque apenas na década de 70 . Esse fato sugere que é relevante que busquemos pesquisar mais sobre a afetividade e como este fenômeno pode influenciar o aprendizado em nossas escolas, de modo a contribuir para a prática do professor e para o aprendizado dos alunos. 
Uma das primeiras medidas tomadas pela instituição de ensino em questão foi o envio de aulas gravadas aos alunos, o que se mostrou ineficaz uma vez que percebemos que alguns alunos não estavam assistindo a essas aulas e, dos que assistiam, muitos não estavam compreendendo o que estava sendo mostrado pelos professores nos vídeos. Conjecturamos, assim, que um dos motivos para o não aproveitamento era a falta de interação entre o professor e o aluno.

Neste contexto, este trabalho, que apresenta um recorte da dissertação de mestrado em Ensino de Matemática desenvolvida pelo primeiro autor, visa discutir como a relação professoraluno pode influenciar no processo de ensino-aprendizagem, investigando se e como essa relação foi abalada, tendo em vista a necessidade de aulas remotas. Para tanto, além de uma pesquisa bibliográfica, propomos um questionário a alunos do $9^{\circ}$ ano, a fim de saber o que sentem em relação a ausência do contato presencial com seus professores.

Nosso trabalho está organizado da seguinte forma: na primeira seção, discorremos sobre como as aulas virtuais surgiram e como se tornaram tão importantes no ano de 2020, ressaltando algumas dificuldades encontradas por professores e alunos com o ensino remoto; no item subsequente, discutimos a relevância da afetividade e a relação professor-aluno para a construção do conhecimento; e na terceira seção, trazemos os resultados encontrados nas análises das respostas ao questionário, discutindo se e de que maneira a ausência da relação professor-aluno de modo presencial afetou o aprendizado dos alunos.

\section{O ENSINO DE MATEMÁTICA REMOTO NO PERÍODO PANDÊMICO DA COVID-19}

Embora o avanço das Tecnologias da Informação e Comunicação (TIC) no Brasil tenha recebido destaque a partir do século XXI, seu uso voltado para o ensino em nosso país começou no século XX, seja por meio de correspondências, rádio ou televisão. A título de exemplo, podemos citar o Telecurso $2^{\circ}$ Grau, surgido em 1977 da parceria entre a TV cultura, outrora chamada Fundação Padre Anchieta, e a Fundação Roberto Marinho. O programa consistia na exibição de aulas de 15 minutos e eram divididas por matérias. O propósito da iniciativa era levar educação básica para quem não possui acesso formal e presencial, como em municípios distantes e para pessoas em situação de defasagem idade-ano (ALVES, 2011).

Entretanto, é preciso notar que a modalidade de aulas a distância se diferencia do ensino remoto, tema que causou dúvidas e discussão no início das aulas no período de isolamento social. Para entender o como se dá o ensino de Matemática a distância, podemos nos embasar nos escritos de Barragan (2015), o qual nos diz que 
O aprendizado da matemática é de suma importância. Sua necessidade se evidencia na maioria das tarefas rotineiras, bem como é componente curricular de muitos cursos superiores, uma vez que é elemento imprescindível em diversas atividades profissionais. Em paralelo, a modalidade a distância tem sido a opção de muitos universitários, pois em tempos de tecnologia facilmente acessível é o curso universitário que vai ao aluno, otimizando seu tempo e ampliando suas condições para acessar o conteúdo a qualquer momento. (BARRAGAN, 2015, p. 2)

Assim, podemos entender que a educação a distância $(\mathrm{EaD})$ foi desenhada para prestar atendimento, aplicar atividades, aulas e outras demandas em um ambiente virtual de aprendizagem, com apoio de tutores e recursos tecnológicos que favorecem o ensino. Ou seja, ainda que haja o uso da tecnologia, faz-se necessário algum acompanhamento de forma presencial. Deste modo, na educação a distância, o aprendiz torna-se o protagonista da sua aprendizagem, pois necessita organizar-se, planejar suas atividades de estudo, usar de modo eficaz e adequado os momentos (presenciais ou a distância) com os tutores, entre outras atividades (BARRAGAN, 2015). Portanto, trata-se de uma metodologia ativa em que o aprendiz é o centro do processo de ensino-aprendizagem.

Em contrapartida, ao se tratar de ensino remoto, temos esse modo de ensino como algo emergencial, que pode ser considerado uma solução temporária para o prosseguimento das atividades pedagógicas tendo como principal ferramenta a internet. Para tal modalidade, Basso, Fioratti e Costa (2020, p. 200) destacam que

Com as aulas presenciais suspensas desde o mês de março de 2020, muitas Secretarias Estaduais e Municipais de Educação, passaram a planejar e aplicar programas emergenciais de ensino remoto por meio de entrega de materiais impressos, aulas gravadas, atendimentos online via plataformas digitais ou aplicativos de celulares.

Assim, a Educação a Distância se configura como a organização e o planejamento administrativo, técnico, logístico e pedagógico da educação como tipo de configuração para o ensino-aprendizagem, já o Ensino Remoto ou aula remota representa uma modalidade emergencial que pressupõe o distanciamento geográfico de professores e estudantes, com transposição do ensino presencial para os meios digitais, com foco na informação e suas formas de transmissão, o qual pode se dar de modo síncrono ou assíncrono.

Importa salientar, conforme destacam Santos e Scheffer (2012), que não basta o mero uso das tecnologias nas aulas, é necessário repensar os modos tradicionais de ensino, trazendo mudanças nas posturas de alunos e professores. Se por um lado o docente deve buscar métodos de ensino dinâmicos, criativos, interativos, por outro, o discente deve ter uma postura mais ativa, sendo o protagonista de sua aprendizagem. Neste sentido, com a adoção das aulas 
remotas, muitos professores não se sentiam preparados para a realização das aulas virtuais e tiveram que adaptar-se rapidamente para essa nova tarefa.

Uma pesquisa do Instituto Península, reportado pelo Estadão (CAFARDO, 2020) foi feita com 7734 professores de escolas públicas e privadas e nela mostra que $83 \%$ deles não estão preparados a ensinarem a distância. E com razão. Como mostra o mesmo estudo, 55\% não têm recebido treinamento para atuar online (ARAÚJO; SILVA; SILVA, 2020, p. 5).

Particularmente no caso do ensino da Matemática, essa preocupação com as mudanças pode se tornar ainda maior, tendo em vista os modos tradicionais geralmente empregados, nos quais o professor é o protagonista e a aula segue um roteiro de explicação do conteúdo e fixação por parte dos alunos com a resolução de listas de exercícios.

A disciplina de matemática fazendo parte de todos os repertórios de avaliação internacionais e nacionais, com suas pontuais finalidades, depara-se com formas tradicionais, quase "sacralizadas" de ensinar, e a necessidade de encaminhar atividades de forma remota, fazendo emergir as teorias críticas e pós-modernas de concepção curricular na matemática (BASSO; FIORATTI; COSTA, 2020, p. 211).

Contudo, ressaltamos que não foram apenas os professores que sofreram com a nova realidade da sala de aula, os discentes também enfrentaram desafios em se adaptar. Conforme explicam Calvani, Fini e Ranieri (2008), nossos alunos precisam desenvolver as chamadas competências digitais na educação e para isso, é fundamental que eles utilizem as Tecnologias da Informação e Comunicação (TICs) de maneira adequada e que desenvolvam as habilidades do futuro, as chamadas competências digitais, a saber:

Ser capaz de explorar e enfrentar as novas situações tecnológicas de uma maneira flexível, para analisar, selecionar e avaliar criticamente os dados e informação, para aproveitar o potencial tecnológico com o fim de representar e resolver problemas e construir conhecimento compartilhado e colaborativo, enquanto se fomenta a consciência de suas próprias responsabilidades pessoais e o respeito recíproco dos direitos e obrigações (CALVANI; FINI; RANIERI, 2008, p. 186).

Além dos desafios com relação ao domínio das ferramentas tecnológicas, veremos também que o isolamento trouxe dificuldades de ordem emocional, pelo isolamento entre discentes e docentes. Diante desse cenário, cabe refletir e buscar alternativas para superar as dificuldades, no sentido de amenizar as aflições, seja dos professores ou dos alunos.

\section{RELAÇÃO PROFESSOR-ALUNO E O ASPECTO EMOCIONAL NO ENSINO-APRENDIZAGEM DA MATEMÁTICA}

Ao ir à escola, além de aprender os conceitos acadêmicos, as crianças e os jovens aprendem saberes mais amplos, também relevantes, como interagir e se comportar em sociedade, por exemplo. Para muitos, a escola tem até mesmo um papel de refúgio, onde o 
discente esquece os problemas do lar, conforme já fora constatado por Araújo, Silva e Silva (2020). É neste aspecto que a discussão sobre as relações interpessoais e do aspecto emocional no contexto escolar se tornam relevantes. Para tal discussão, abordamos algumas contribuições do filósofo e psicólogo Henri Wallon ${ }^{1}$ (1879 - 1962).

Quando as pessoas se sentem seguras, em um ambiente que consideram agradável, elas tendem a aprender com mais facilidade e, embora se sentir seguro dependa também de outros fatores externos à escola, cabe ao professor, dentro de sala, criar um ambiente propício ao aprendizado do aluno, uma vez que sabemos que a relação entre professor e aluno é fundamental para o processo de ensino-aprendizagem (MAHONEY; ALMEIDA, 2005; SALLA, 2011).

Segundo Salla (2011), a emoção é contagiosa: se o professor se mostra feliz, entusiasmado, pode transmitir tais sentimentos aos seus alunos no contexto da sala de aula. Assim, é importante que o docente crie um ambiente de acolhimento e receptividade.

A profissão docente caracteriza a dualidade entre saber e afeto, pois o professor está
sempre envolvido com pessoas, vivenciando relações interpessoais complexas e, ao
mesmo tempo, possui um acesso ao saber que tem função estruturante na constituição
do sujeito, mas que também não garante a segurança do seu "todo profissional". Isto
porque ter domínio de conteúdos não é o suficiente para que o professor possa realizar
sua função (MENDES E BACCON, 2015, p. 3).

Embora não seja fácil definir os conceitos relacionados aos estudos da afetividade, há certo consenso em discriminar processos afetivos como estados que nos dão as sensações de prazer (desprazer) ou de algo agradável (desagradável) (MAHONEY; ALMEIDA, 2005). Nesse sentido, é importante que o professor leve em consideração o aspecto da afetividade em suas aulas, pois "um bom educador é aquele que observa seus alunos e a forma como eles agem e lidam com as coisas. O corpo do sujeito está sempre revelando as sensações de bem ou malestar" (SALLA, 2011, p. 3).

Para Wallon (2007), só haverá crescimento se houver perda: para deixar de ser um bebê, a criança precisa perder o bebê que há em si, assim como para que o adulto possa se tornar um adulto, ele precisa perder o jovem que há dentro de si, ou seja, a linguagem, os gostos e sua personalidade vão se alterando à medida que o sujeito cresce. $\mathrm{O}$ autor defende que a criança se desenvolve em cinco estágios, marcados por crises e conflitos, rupturas e sobreposições. Portanto, nossas experiências vividas no coletivo são de grande importância para a constituição de quem seremos no futuro.

\footnotetext{
${ }^{1}$ Nascido na França, Henri Paul Hyacinthe Wallon foi psicólogo, médico, filósofo e político. Tornou-se conhecido por sua obra sobre a psicologia do desenvolvimento, na qual assume uma postura notadamente interacionista.
} 
Estas revoluções de idade para idade não são improvisadas por cada indivíduo. São a própria razão da infância, que tende para a edificação do adulto como exemplar da espécie. Estão inscritas, no momento oportuno, no desenvolvimento que conduz a esse objetivo. As incitações do meio são sem dúvida indispensáveis para que elas se manifestem e quanto mais se eleva o nível da função, mais ela sofre as determinações dele: quantas e quantas atividades técnicas ou intelectuais são à imagem da linguagem, que paca cada um é a do meio! (WALLON, 2007, p. 210)

Assim, conforme salienta o filósofo, o potencial genético herdado por alguém depende também do meio em que a pessoa está inserida, isto é, somos em alguma medida moldados pelo ambiente em que interagimos. Os estágios de desenvolvimento mencionados podem ser sistematizados no quadro a seguir.

Quadro 1 - Teoria dos Estágios de Henri Wallon

\begin{tabular}{|c|c|}
\hline Estágio & Faixa-Etária \\
\hline Impulsivo e Emocional & 3 a 12 meses \\
\hline Sensório-motor e Projetivo & 1 a 3 anos \\
\hline Personalismo & 3 a 6 anos \\
\hline Categorial & 6 a 11 anos \\
\hline Puberdade e Adolescência & Acima de 11 anos \\
\hline
\end{tabular}

Fonte: Elaborado (2021) pelos autores a partir de Wallon (2007).

Acreditamos que o fato de o professor tentar entender em qual estágio o aluno se encontra facilitará o processo de ensino-aprendizagem, pois ele pode criar atividades adequadas, de acordo com os discentes que atende. O público de nossa pesquisa é composto por alunos do $9^{\circ}$ ano do Ensino Fundamental, cujo estágio de desenvolvimento se aproxima do quinto, qual seja, Puberdade e Adolescência.

Segundo Wallon (2007), este estágio é marcado pela oposição entre o sujeito e outro, levando-o a refletir sobre questões como "quem sou eu?" "O que quero para o futuro?" e um ensino facilitador da aprendizagem deve levar em consideração tais aspectos, abrindo espaço para expressão e discussão dessas questões (MAHONEY; ALMEIDA, 2005).

Oestreich, Costa e Goldschmidt (2018) argumentam que é necessário romper a dicotomia entre afeto e cognição, isto é, precisamos superar a ideia de que o ensino de Matemática precisa ser algo severo, onde não é permitido sorrir; pelo contrário, o professor não pode estar distante da realidade de seus alunos, este deve estar atento ao bem-estar e às dificuldades dos discentes.

Mahoney \& Almeida (2005), discutindo as ideias de Wallon, destacam que o professor deve, dentre outros aspectos, demonstrar confiança na capacidade do aluno, ensinar buscando promover o desenvolvimento do aluno e de si mesmo, desenvolver tarefas para além da sala de aula, tais como socialização escolar, familiar e profissional, numa integração cognitiva-afetiva e entender que as emoções e sentimentos podem variar de intensidade, em função dos contextos, 
mas que estão presentes na vida de todos os alunos, interferindo de maneira diferente em cada um deles.

Com a pandemia e o consequente isolamento social que impediu o contato interpessoal presencial, em particular nas escolas, muitas pessoas acabaram adquirindo problemas psicológicos, como ansiedade, pânico e depressão (ALMEIDA; SILVA, 2020). Neste sentido, cabe discutir como esse afastamento pode ter influenciado no aprendizado de Matemática.

\section{UM ESTUDO COM ALUNOS DO 9 ANO DO ENSINO FUNDAMENTAL}

Com o intuito de avaliar os impactos desse novo modelo de ensino acerca do aspecto emocional, desenvolvemos um questionário para os alunos do $9^{\circ}$ ano de uma escola da rede privada do Estado do Pará. Na escola em questão, foi adotado o ensino remoto, com aulas online, vídeos gravados pelos docentes e material de estudo disponibilizado pela instituição.

Nossa pesquisa apresenta uma abordagem quali-quantitativa, na medida que se vale não apenas dos dados estatísticos, mas também da subjetividade e dos referenciais teóricos adotados. Conforme Baptista (1999), a fim de melhor compreender a realidade, é necessário mesclar as abordagens qualitativa e quantitativa, no sentido de cooperação. Assim, para nossas análises apresentamos os percentuais relativos às questões abordadas, seguidos de breve discussão. Por outro lado, a investigação tem caráter exploratório, uma vez que busca dar alguma contribuição no entendimento a respeito do impacto no aprendizado, tendo em vista a ruptura na relação presencial entre professor e alunos.

Deixamos nosso questionário em aberto por um mês, durante 02/11/2020 a 30/11/2020 e, de acordo com os dados do Google Forms, 60 alunos responderam ao questionário. Ressaltamos que a escola onde a pesquisa foi realizada conta com 5 unidades e 8 turmas de $9^{\circ}$ ano, num total de 200 alunos, assim, o percentual de alunos da faixa etária que respondeu a nossa pesquisa foi de $30 \%$. Ressaltamos que a elaboração do formulário se baseia em nossa experiência de sala de aula, a qual nos levou a suspeitar que a ruptura abrupta das aulas presenciais poderia ser um fator de dificuldade para os discentes. Por outro lado, tendo em vista este texto tratar-se de um recorte de uma pesquisa mais ampla, escolhemos algumas perguntas para a análise seguinte, aquelas que julgamos pertinentes ao tema da afetividade e o aprendizado no período de aulas remotas

Pergunta 01 - O que você sentiu quando soube que as aulas de matemática não seriam mais presenciais durante o período de isolamento? 
Figura 1 - Respostas à pergunta 01

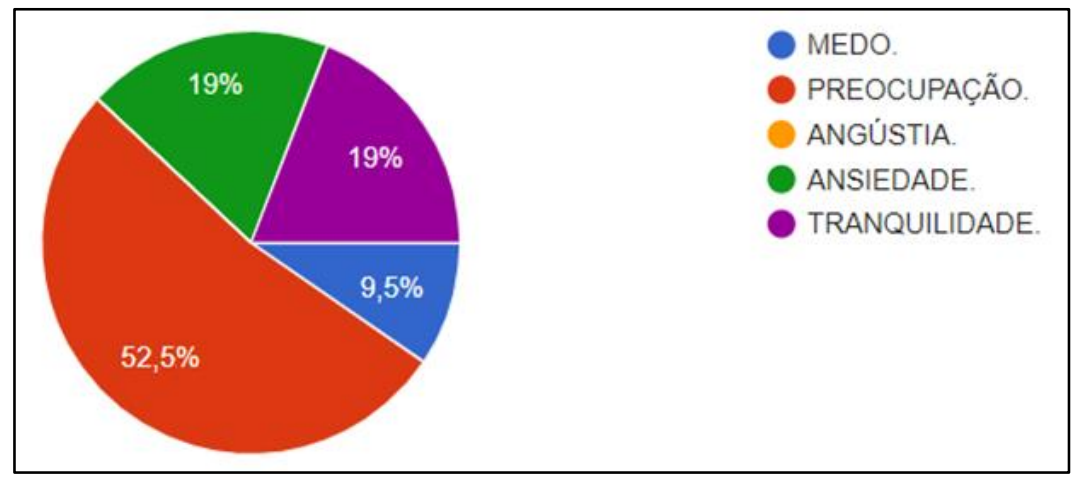

Fonte: Dados constituídos durante a pesquisa.

Com base nas respostas, podemos inferir que o sentimento mais presente na mente dos alunos foi a preocupação, isso porque, segundo acreditamos, teriam de lidar com uma nova forma de ensino, sem o contato presencial com o professor para ajudar ou orientá-los. Conforme constataram Almeida e Silva (2020) em pesquisa realizada a esse respeito entre maio e abril de 2020, 29,4\% dos brasileiros avaliou que a sua saúde piorou; $45 \%$ tiveram problemas no sono, $40 \%$ apresentaram, frequentemente, sentimento de tristeza e 52,5\% de ansiedade/nervosismo. E, nesse contexto, sabemos que as emoções podem atrapalhar o aprendizado. Conforme corrobora Salla (2011, p. 3) "O medo, por exemplo, pode inibir a aprendizagem, pois a emoção impossibilita que o racional atue de forma efetiva".

Pergunta 02 - Após suas primeiras aulas de matemática no ensino remoto emergencial, qual sentimento lhe representaria?

Figura 2 - Respostas à pergunta 02

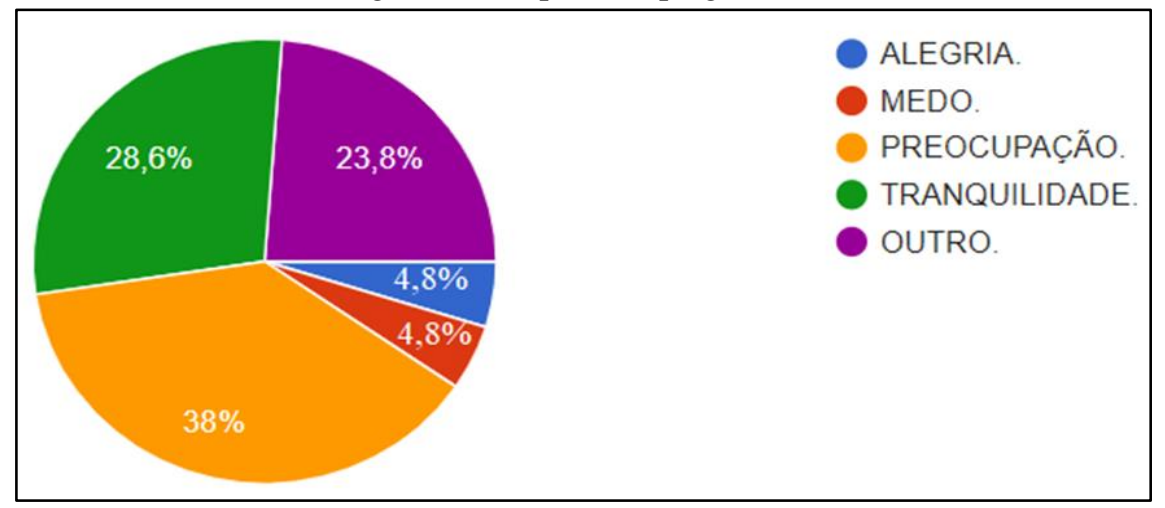

Fonte: Dados constituídos durante a pesquisa.

Percebemos que, após algumas aulas, o sentimento dos alunos mudara, contudo, cerca de $40 \%$ dos alunos ainda se sentiam preocupados e, nas palavras de Wallon (2007), o aluno não aprenderá caso não se sinta seguro. Deste modo, além de todas as preocupações com a biossegurança, é importante que dediquemos parte do tempo em busca de estratégias para tentar amenizar as preocupações dos alunos. Conforme nossa experiência nos fez notar, um destes 
problemas é a transição entre o ensino fundamental e o ensino médio, visto que o aumento das responsabilidades deixa alguns de nossos alunos preocupados.

Pergunta 03 - O que você mais sentiu falta em relação à escola nesse período de isolamento social?

Figura 3 - Respostas à pergunta 03

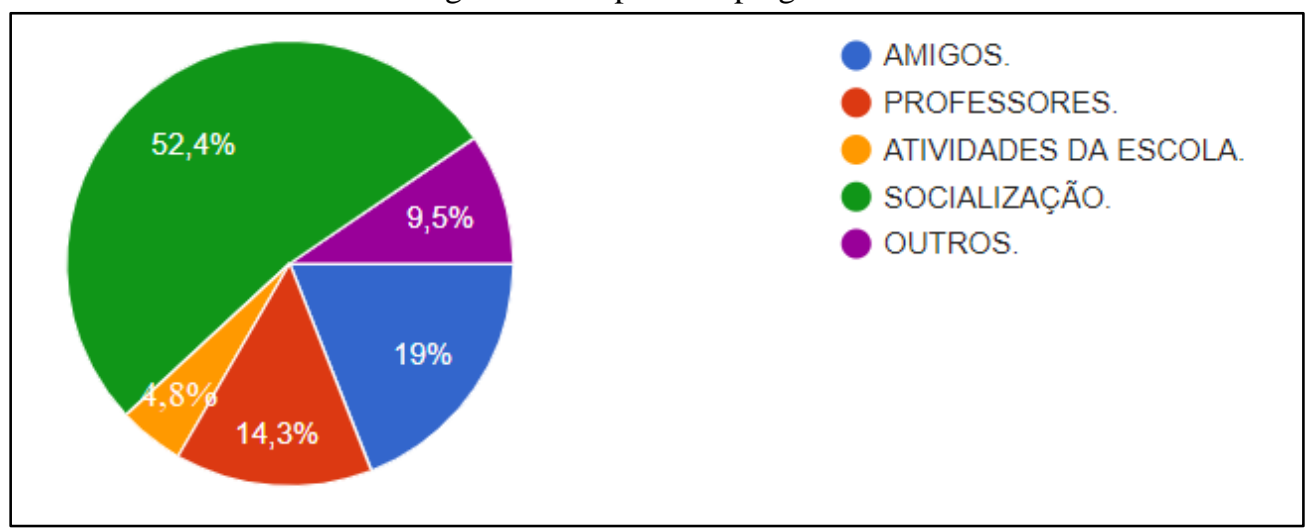

Fonte: Dados constituídos durante a pesquisa.

Retornando a frase de Aristóteles, somos seres sociáveis, e sob tal aspecto, 95\% dos alunos sentiu falta da interação com os outros, ou seja, da socialização com os amigos e professores, o que corrobora com nossas concepções de como as relações afetivas são importantes para o processo de ensino aprendizagem. Discutindo as relações entre a afetividade e o desempenho escolar, Moreira (2007) salienta que os sentimentos que permeiam a relação professor-aluno influenciam a motivação pela matéria e consequentemente a melhora no aprendizado.

Pergunta 04 - Qual a sua maior dificuldade no processo ensino e aprendizagem da disciplina matemática durante as aulas em período de isolamento social?

Figura 4 - Respostas à pergunta 04

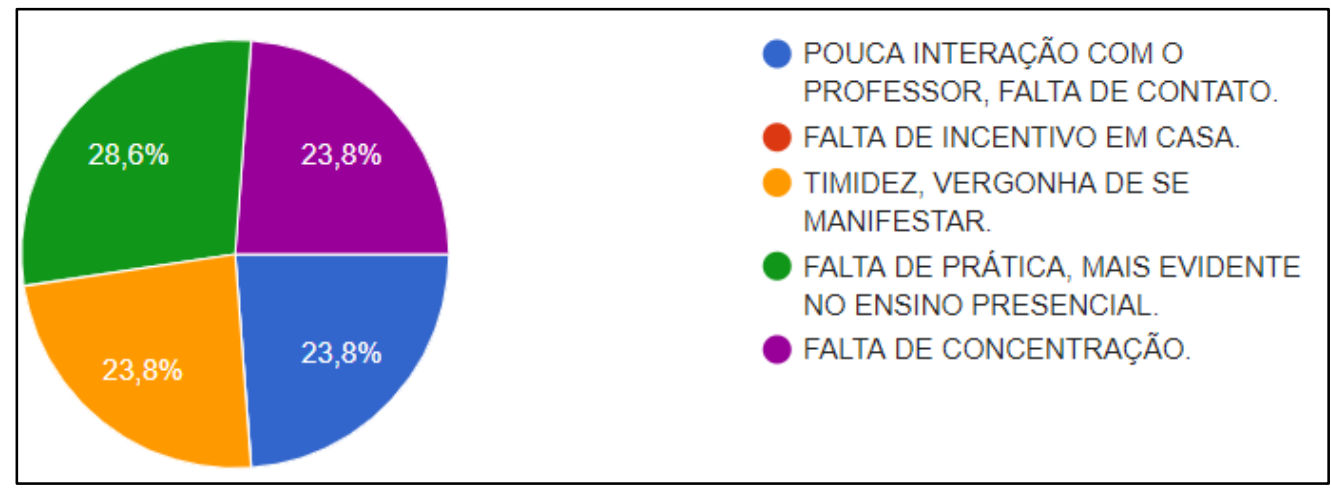

Fonte: Dados constituídos durante a pesquisa.

Buscamos entender as dificuldades dos alunos e percebemos que são muitas, pois a única resposta que não fora marcada foi a "Falta de incentivo em casa", as demais ficaram 
homogeneamente distribuídas com cerca de $25 \%$ da preferência dos alunos, destacando-se timidamente a falta de prática, mais evidente no ensino presencial. A falta de contato presencial com o professor $(23,8 \%)$ pode causar também a timidez em se manifestar $(23,8 \%)$, uma vez que o ambiente é outro, as relações são outras e os discentes podem se tornar introspectivos e inseguros em se manifestar, tendo em vista também a novidade de aulas remotas por meio das ferramentas tecnológicas, e todos esses sentimentos afetam o rendimento. Ora, não podemos esquecer que antes de serem discentes, estes são seres humanos, movidos por emoções, angústias, tristezas e alegrias (OESTREICH; COSTA; GOLDSCHMIDT, 2018).

Pergunta 05 - Você considera a interação, troca de informações com o professor no modo presencial essencial para o seu aprendizado?

Figura 5 - Respostas à pergunta 05

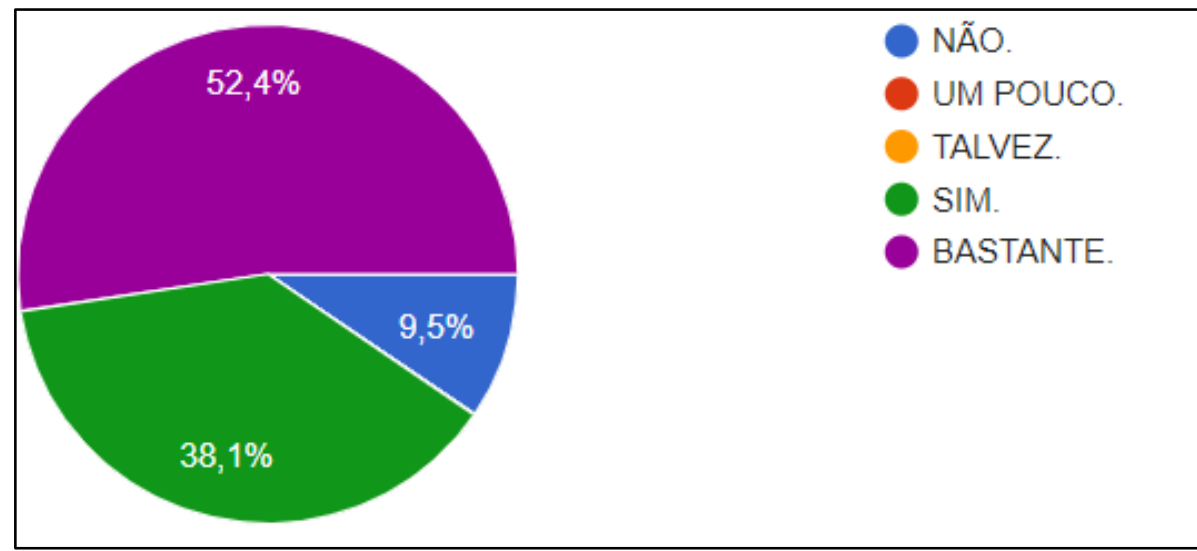

Fonte: Dados constituídos durante a pesquisa

Aqui trazemos as concepções de Wallon (2007) para a prática do ensino de matemática, mais de $90 \%$ dos alunos consideram que a relação de interação, no modelo presencial, entre professor e aluno é fundamental para o processo de ensino-aprendizagem. Conforme Moreira (2007), a cognição tem forte relação com a afetividade, por outro lado, como vimos, um ambiente receptivo colabora para uma aprendizagem mais efetiva e as relações entre professor e aluno podem ir além do ato de ensinar a lição.

Notamos que a escola tem papel fundamental na formação do aluno e, o professor deve ter um papel de destaque, pois, por vezes, os mesmos são "espelhos" para seus alunos, servindo como fonte de inspiração para os mesmos (MOREIRA, 2007, p.31).

Assim, nas respostas dos alunos, notamos que a ausência presencial do docente pode ser um fator que o desestimula, prejudicando seu aprendizado.

Pergunta 06 - Se você tivesse que escolher um método de ensino para 2021 e seguir sua preparação e formação estudantil no ensino médio, qual seria? ${ }^{2}$

\footnotetext{
${ }^{2}$ Importa informar que foi esclarecido o significado dos termos "remoto", "híbrido" e "presencial" nesse contexto. 
Figura 6 - Respostas à pergunta 06

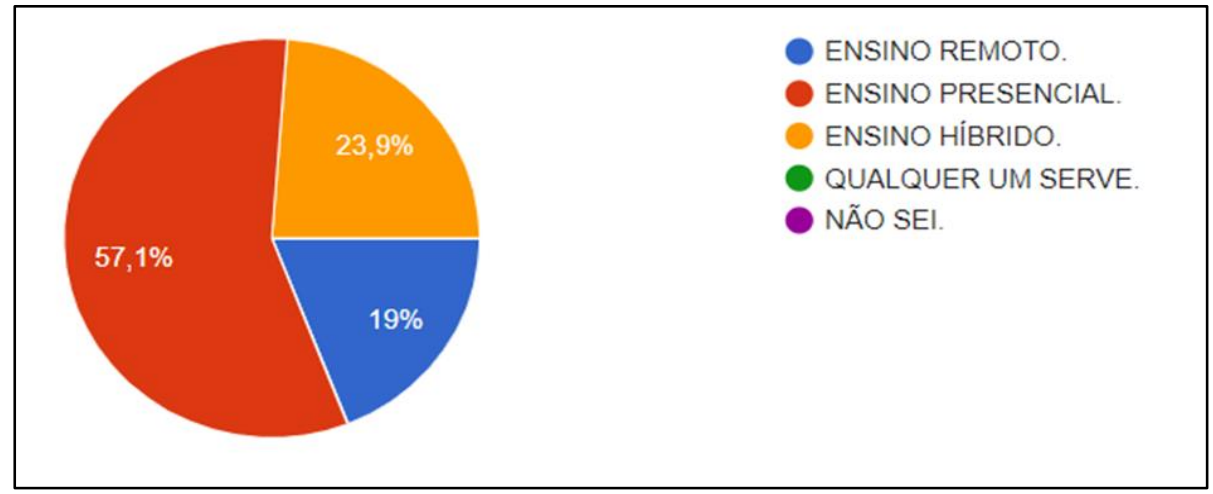

Fonte: Dados constituídos durante a pesquisa

Os dados referentes a essa pergunta corroboram o que temos discutido até aqui: mais de $80 \%$ deles gostariam de um ensino com algum contato presencial com o professor, sendo que mais da metade prefere o ensino presencial.

Pergunta 07 - Como você classificaria seu grau de aprendizado em matemática no ano de $2020 ?^{3}$

Figura 7 - Respostas à pergunta 07

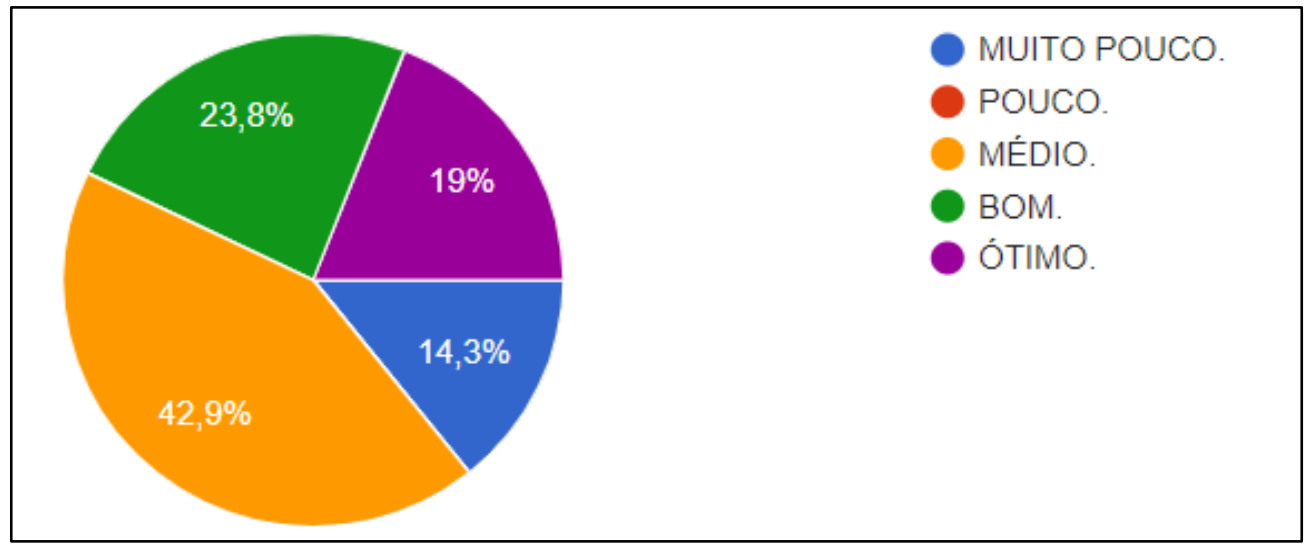

Fonte: Dados constituídos durante a pesquisa

Percebemos que apenas $33 \%$ dos alunos afirmaram que o grau de aprendizagem em 2020 foi satisfatório, ou seja, bom ou ótimo e, com isto, percebemos que os alunos sentem que há lacunas em seu processo de aprendizagem. Embora seja possível discutir as fragilidades no aprendizado sob diversos aspectos (dificuldades com as ferramentas tecnológicas, dificuldades em relação às metodologias adotadas no ensino remoto, a familiares doentes, etc.), se retomarmos às questões anteriores nas quais os alunos apontam a ausência presencial do docente como fator que pode prejudicar o aprendizado, podemos inferir que os números que

\footnotetext{
${ }^{3}$ Aqui os termos "Pouco" e "Muito pouco" podem ter limites tênues, o que talvez explique o fato de que "Pouco" não foi escolhido por nenhum discente. De todo modo, as respostas indicam que mais da metade dos alunos considerou seu aprendizado não foi bom ou ótimo.
} 
representam a questão 07 são explicados também pelo distanciamento das relações entre discentes e docentes.

Deste modo, por meio deste item, reiteramos as palavras de Mahoney e Almeida (2005):

Importante em qualquer idade, o acolhimento da criança e do jovem pelo grupo familiar, pelo grupo de amigos, grupo de colegas e professores, o acolhimento do professor pela direção, pelos seus pares, pelo seu entorno e pelos seus alunos. A sala de aula - uma oficina de relações - é um espaço de acolhimento. (MAHONEY; ALMEIDA, 2005, p.15)

Dito isto, notamos a importância do ambiente escolar para os alunos, o local onde eles socializam e agem como seres pensantes de uma sociedade e, ainda que os alunos se relacionem por meio de aplicativos de mensagens instantâneas, a relação interpessoal durante as aulas presenciais é essencial para a formação dessas crianças enquanto indivíduos que vivem em sociedade.

Assim como compreendido no referencial teórico, notamos a forte relação entre o aspecto cognitivo e o afetivo dos alunos, enfatizando que estes precisam sentir-se seguros para que possam melhor aprender e a relação com o professor é um dos fatores principais para que adquiram essa autoconfiança.

Sob este viés, visando a construção do aluno enquanto cidadão, Demizu et al. (2015) salientam que

\begin{abstract}
As grandes transformações ocorridas na sociedade, bem como, as constantes mudanças de informações, refletem diretamente no ensino, tornando assim, a escola não somente como uma transmissora de conhecimentos, e sim em um ambiente inovador, possibilitando ao aluno, uma compreensão de conteúdos que proporcione uma educação de qualidade, através de uma aula que valorize a invenção e a descoberta, desenvolvendo trocas, experiências, afetividade e o pensamento crítico e reflexivo (DEMIZU et al., 2015, p.3).
\end{abstract}

Desta forma, a partir do que foi discutido, notamos a relevância da emoção e da afetividade nas situações de ensino e de aprendizagem e desta maneira, caso o professor tenha a oportunidade de entender melhor os conceitos propostos por Wallon (2007), poderá enriquecer sua atividade docente, conquistando a confiança dos alunos e, deste modo, contribuir para uma melhor aprendizagem.

\title{
5 CONSIDERAÇÕEs FinAIS
}

Buscamos neste trabalho discutir a importância das relações entre professor-aluno e a afetividade no processo de ensino e aprendizagem em aulas remotas. $\mathrm{O}$ ano de 2020 foi muito desafiador, pois além de ser uma novidade para alunos, professores e gestores de ensino, os 
professores já enfrentavam desafios no ensino da matemática em aulas presenciais e, quando trabalhamos no sistema remoto, esse grau de dificuldade mostrou-se ainda mais desafiador.

Embora se discuta os benefícios que as aulas remotas podem ter trazido e que aspectos delas podem ser aproveitados no futuro, ao que parece, a relação do professor e aluno em sala de aula não poderá ser facilmente substituída. No decorrer de nossa pesquisa, encontramos nos textos de Wallon (2007) que a relação professor-aluno é fundamental para a construção do conhecimento do aluno, pois ainda que o estudante seja o agente do seu caminho, ele só poderá conceber esse conhecimento se tiver um suporte para tal e, cabe a nós, professores, como mediadores, oferecermos tal alicerce.

Na condição de mediador, percebemos que muitos alunos têm dificuldade em interagir, o que, no presencial, era sanado por meio de um "levantar a mão", chamar o professor em particular e tirar uma dúvida, a relação de confiança professor-aluno era construída ali, contudo, no sistema remoto, não há essa privacidade, muitos alunos não se sentem seguros para expressar seus medos, suas angústias, suas dúvidas.

Deste modo, acreditamos que com a realização desta pesquisa - na qual pudemos melhor entender quais as dificuldades encontradas pelo aluno durante o isolamento e de como a falta de interação com o professor afeta seu processo de aprendizagem - podemos tirar boas lições para a retomada das atividades presenciais a saber: a relevância de se criar um ambiente de confiança e de receptividade nas aulas, a importância de o professor mostrar prazer no que faz e a necessidade de o docente acompanhar o desenvolvimento e evolução de seus alunos, a fim de melhor planejar e ministrar suas aulas.

\section{REFERÊNCIAS}

ALMEIDA, Wanessa da Silva; SILVA, Danilo Rodrigues Pereira. Mudanças nas condições socioeconômicas e de saúde dos brasileiros durante a pandemia de COVID-19. Rev. bras. epidemiol. Rio de Janeiro, v. 23, 2020. Disponível em http://www.scielo.br/scielo.php?script=sci_arttext\&pid=S1415790X2020000100211\&lng=en\&nrm=iso. Acesso em 29 abr. 2021.

ALVES, Lucineia. Educação a distância: conceitos e história no Brasil e no mundo. Revista Brasileira de Aprendizagem Aberta e a Distância, São Paulo, Vol. 10, p. 83-92, 2011.

ARAÚJO, Francisco Willame Gomes; SILVA, Emanoel Marcilio de Abrantes Gadelha; SILVA, Roberlandia de Abrantes Gadelha. Uma análise da educação matemática durante a pandemia de covid-19. Anais VII CONEDU - Edição Online... Campina Grande: Realize Editora, 2020. 
BAPTISTA, Dulce Maria Tourinho. O debate sobre o uso de técnicas qualitativas e quantitativas de pesquisa. In: MARTINELLI, Maria Lucia (Org.). Pesquisa Qualitativa: um instigante desafio. São Paulo: Veras, 1999.

BARRAGAN, Raquel Farina. Matemática: é possível aprender a distância? Anais do XIX Encontro Brasileiro de Estudantes de Pós-Graduação em Educação Matemática, Juiz de Fora-MG, Universidade Federal de Juiz de Fora/MG, 2015.

BASSO, Silvia Eliane de Oliveira; FIORATTI, Netúlio Alarcon; COSTA, Maria Luisa Furlan. A Matemática Diante da Possibilidade do Ensino Remoto: uma discussão curricular. Plurais Revista Multidisciplinar, v. 5, n. 2, p. 192-213, 2020. https://doi.org/10.29378/plurais.2447-9373.2020.v5.n2.192-213

CALVANI, Antonio; FINI, Antonio; RANIERI, Maria. Assessing digital competence in secondary education. Issues, models and instruments. Issues in information and media literacy: education, practice and pedagogy, p. 153-172, 2008.

DEMIZU, Fabiana Silva Botta et al. Reflexões sobre teorias da aprendizagem para o ensino de ciências: Piaget x Vygotsky. Anais do XII Congresso Nacional de Educação, CuritibaPR, 2015.

KIROUAC, Gille. Les émotions". In: Richele, M. et al. Traité de Psychologie Experimentale. Paris, PUF, 1994.

MAHONEY, Abigail Alvarenga; DE ALMEIDA, Laurinda Ramalho. Afetividade e processo ensino-aprendizagem: contribuições de Henri Wallon. Psicologia da Educação. Programa de Estudos Pós-Graduados em Educação: Psicologia da Educação. ISSN 2175-3520, n. 20, 2005.

MENDES, Thamires Christine; BACCON, Ana Lúcia Pereira. Profissão docente: o que é ser professor? Anais do XII Congresso Nacional de Educação, Curitiba-PR, 2015.

MOREIRA, Eline Dias. A importância da afetividade no processo de ensino-aprendizagem de matemática. Dissertação (Mestrado Matemática) - Mestrado Professional em Matemática. Pontifícia Universidade Católica. São Paulo - SP, 2007.

OESTREICH, Laura; COSTA, Daniela; GOLDSCHMIDT, Andréa Inês. O olhar cuidadoso do educador: caminhos percorridos. Revista Prática Docente. v. 3, n. 1, p. 366-385, 2018.

SALLA, Fernanda. Henri Wallon e o conceito de emoção. Nova Escola (online), 2011. Disponível em: https://novaescola.org.br/conteudo/114/henri-wallon-conceito-emocao. Acesso em 14 de março de 2021.

SANTOS, Bruna Cassol; SCHEFFER, Nilce Fátima. Aprendizagem matemática com o auxílio de ambientes virtuais. PERSPECTIVA, Erechim. v.36, n.135, p.7-13, 2012.

WALlON, Henri. A evolução psicológica da criança. São Paulo: Martins Fontes, 2007. 